\title{
Evolution of Laparoscopy through the Ages
}

\author{
${ }^{1}$ Meenakshi E Yeola (Pate), ${ }^{2}$ Dilip Gode, ${ }^{3}$ Akshay K Bora
}

\begin{abstract}
The field of laparoscopic surgery has experienced tremendous growth in the last three decades. The important events among them have been the invention of incandescent bulbs by Thomas Edison, the development of lens scopes (1870-1980s), the invention of rod lens system by Hopkins (1950s), the fiberoptic cold light transmission (1960s), and the computer chip video camera (1980s).

Technological advancements have produced progressively smaller laparoscopic instruments and higher quality imaging that allow laparoscopic surgeons to perform precise dissection with minimal bleeding through most dissection planes, and the major limitations of standard laparoscopy procedures are overcome with these advances.

The introduction and evolution of minimally invasive surgery has drastically changed the entire scenario of the ways in which surgeons are treating the patients. With the introduction of various innovative technologies like high-definition television, video systems, integrated digital reporting, head-mounted displays, surgical robotics, virtual reality training, and the integration of various modalities, such as ultrasound, computed tomography, and magnetic resonance imaging, the surgeon has better knowledge of the disease, thereby, treating the patient more effectively.

In this review article, we explore the evolution of laparoscopy through the ages, thereby, making way for further development in the field of minimal access surgery.
\end{abstract}

Keywords: Advancement, History, Laparoscopy, Natural orifice transluminal endoscopic surgery, Robotic surgery, Singleincision laparoscopic surgery.

How to cite this article: Yeola (Pate) ME, Gode D, Bora AK. Evolution of Laparoscopy through the Ages. Int J Recent Surg Med Sci 2017;3(1):40-47.

Source of support: Nil

Conflict of interest: None

\section{INTRODUCTION}

Laparoscopic surgery, whose development has been so impressive in the last two decades, was initially introduced at the beginning of this century by Dimitri Ott,

\footnotetext{
${ }^{1,2}$ Professor, ${ }^{3}$ Resident

${ }^{1,3}$ Department of General Surgery, Jawaharlal Nehru Medical College, Wardha, Maharashtra, India

${ }^{2}$ Department of General Surgery, Datta Meghe Institute of Medical Sciences, Deemed University, Wardha, Maharashtra, India

Corresponding Author: Meenakshi E Yeola (Pate), Professor Department of General Surgery, Jawaharlal Nehru Medical College, Wardha, Maharashtra, India, Phone: +919822189896 e-mail: drmeenu7@rediff.com
}

Georg Kelling, and Hans Christian Jacobaeus. Von Ott inspected the abdominal cavity of a pregnant woman in 1901, and, afterward, Georg Kelling performed a procedure, called "koelioscopie," closer to the definition of modern laparoscopy. In the same year, Jacobaeus published his first report of what he called "Laparothorakoskopie."

In the following years, several authors in Europe and in the United States performed laparoscopic procedures for diagnostic purposes. It was only with the introduction of the rod-lens optical system and of the cold light fiber-glass illumination that laparoscopy became more popular, especially in the gynecologist departments. At this time, laparoscopy in general surgery was mainly performed for the diagnosis of liver disorders and abdominal trauma, until the intuition of Lukichev in 1983 and Muhe in 1985 who performed their personal technique of laparoscopic cholecystectomy in humans. Operative laparoscopy has advanced tremendously over the last two decades, and several operative procedures have been performed by this approach with the help of newer technologies. ${ }^{1}$

The first description dates to Hippocrates in Greece and ancient Romans, for use of a speculum to visualize the rectum and vagina (460-375 BC).

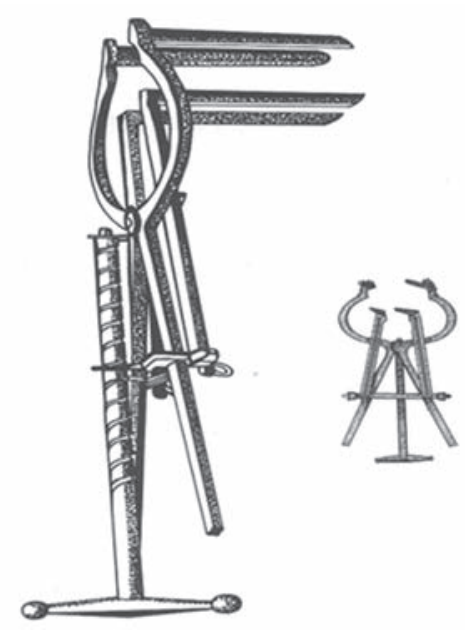

A three-bladed speculum was found in the ruins of Pompeii ${ }^{\star 2,3}$

- Aranzi (1585):

- First used light source

- Focused sunlight through flask of water to look up nose.

- Philip Bozzini (1806):

- Developed an instrument called a Lichtleiter (lightguiding instrument) 
- Antoine Jean Desor Meaux (1853):

- Used Bozzini's Lichtleiter (1867);

- Desor Meaux used an open tube with a series of reflecting mirrors to examine the genitourinary tract, ${ }^{3,4-6}$

- Used open tube to examine female reproductive tract;

- Combined alcohol and turpentine with flame to produce brighter light;

- Side effect - burn.

- Kussmaul (1868):

- First used instrument down the esophagus and into his guinea pig: Sword swallower. ${ }^{4,7}$

- Maximilian Nitze (1848-1906):

- Invented the first cystoscope (Nitze-Leiter cystoscope) in 1879 using an electrically heated platinum wire for illumination.

- In 1887, he modified Edison's light bulb and created the first electrical light bulb for use during urological procedures. ${ }^{5,8}$

- George Kelling, Dresden, Saxony, Germany (1901):

- Performed the first experimental laparoscopy, calling it "Celioscopy."

- Kelling insufflated the abdomen of a dog with filtered air and used a Nitze cystoscope to look inside.

- In 1923, Kelling reported his 22 years of experience with laparoscopy to the German Surgical Society.

- Kelling became one of the earliest advocates of minimally invasive surgery. He encouraged surgeons to use diagnostic laparoscopy in order to spare patients the prolonged and costly stay of a laparotomy. 9

- Hans Christian Jacobaeus (1879-1937):

- 1910: Swedish internist; first thoracoscopic diagnosis with a cystoscope in a human subject.

- Treatment of a patient with tubercular intrathoracic adhesions.

- Jacobaeus performed the first human celioscopy in Sweden in 1910, advocating the technique for the evaluation of patients with ascites. ${ }^{10}$

- Bertram Bernheim (1911):

- First laparoscopy at Johns Hopkins.
- 12-mm proctoscope into epigastric incision on one of Halstead's patients to stage pancreatic cancer.

- Bernheim called his procedure "organoscopy" confirmed findings on laparotomy.

- In 1920, Zollikofer of Switzerland advocated the use of $\mathrm{CO}_{2}$ insufflation instead of filtered air or nitrogen to avoid intra-abdominal explosions and promote rapid absorption of gas. ${ }^{4}$

- Stone introduces the use of gasket to prevent air-leak.

- The concept of introduction of pyramidal trocars by Orndoff is still in practice. ${ }^{11,12}$

- Heinz Kalk (1929) is the founder of the German school of laparoscopy - mostly diagnostic laparoscopy and liver biopsy.

- German physician Kalk introduced forward viewing oblique scope of $135^{\circ}$ view, a more natural angle of vision. ${ }^{7}$

- Boesch (1936)

- First to do fallopian tube ligation. ${ }^{2}$

- Janos Veress (1938):

- Veress needle for safe introduction into abdominal cavity.

- Although Veress created the needle for creation of pneumothorax, it is widely used for creating pneumoperitoneum for laparoscopy.

- In 1938, Veress developed a needle with a springloaded obturator that allowed safe insertion and insufflation of the peritoneal cavity. Thereafter, pneumoperitoneum was established prior to instrumentation of the abdomen.

- Made of surgical stainless steel with a single trap valve. $2 \mathrm{~mm}$ diameter $\times 80 \mathrm{~mm}$ length.

- It consists of an outer cannula with a beveled needle point for cutting through tissues. ${ }^{13}$

- Foriestier introduced illumination by fiberoptic technology with which bright illumination was possible without risk of burns.

- In 1953, Hopkins rod lens system was introduced by Harold Hopkins.

- Improved the clarity and luminance by more than 80 times. $^{14}$

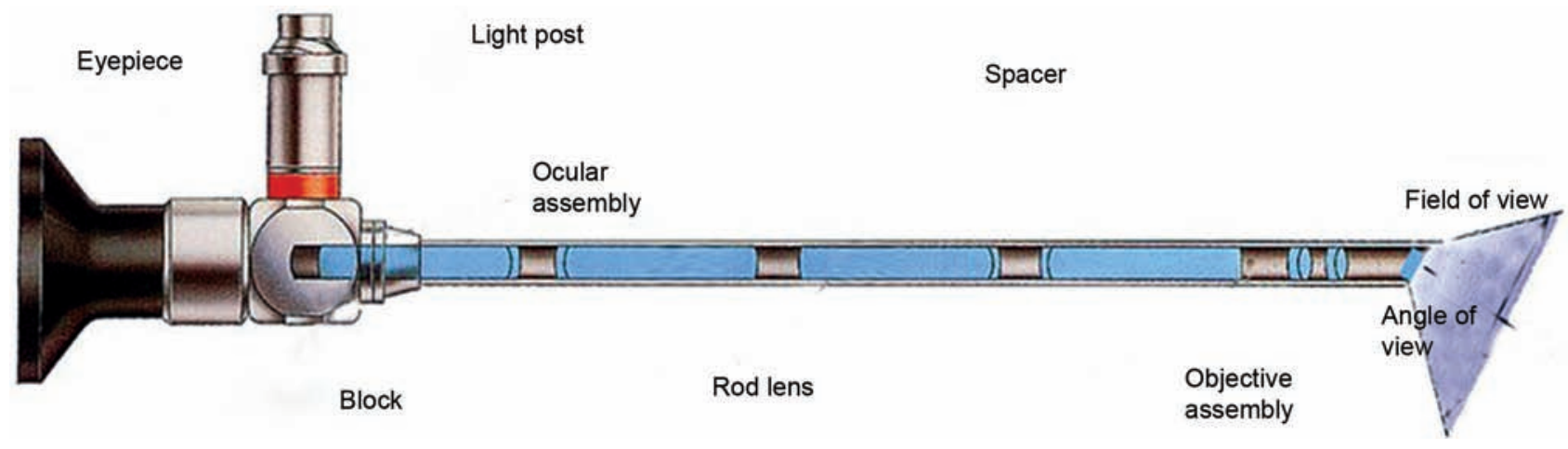




\section{Key Inventions-1950s and 1960s}

- Harold Hopkins and Karl Storz

- Fiberoptic technology (flexible)

- Rigid rod lens telescope-the enabling factor to modern-day key hole surgery

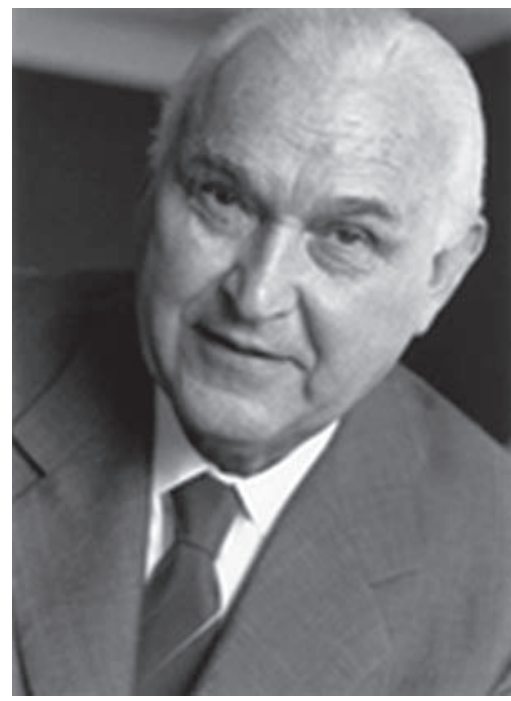

Kurt Semm

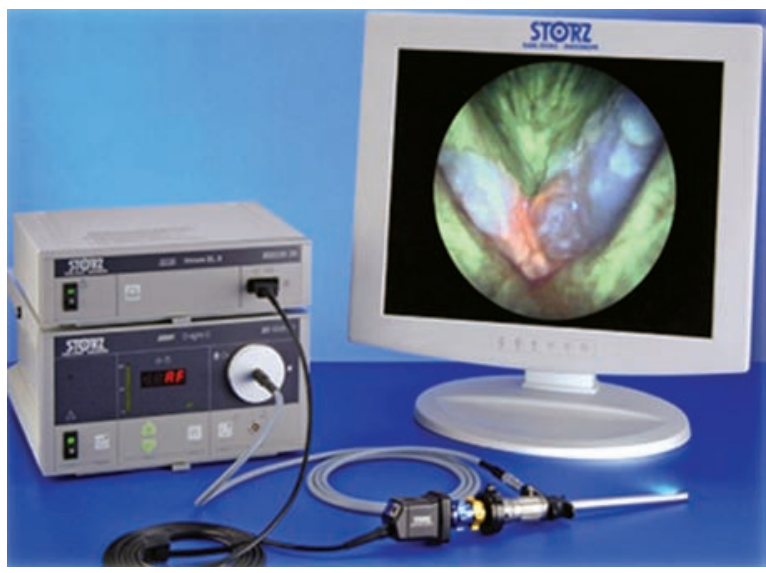

- Kurt Semm (1927-2003):

- In 1966, German engineer and gynecologist introduced automatic insufflator.

- This allowed for safer laparoscopy, and bowel perforations and retroperitoneal vascular injuries subsequently declined.

- Semm developed thermocoagulation, loop knots (EndoLoop), irrigation devices.

- Semm adapted numerous surgical procedures to laparoscopic techniques, including tubal sterilization, salpingostomy, oophorectomy, salpingolysis, and tumor reduction therapy.

- Beyond the realm of gynecologic surgery, Semm popularized laparoscopic procedures, such as omental adhesiolysis, bowel suturing, tumor biopsy, and staging, and, notably, incidental appendectomy (1983). Although interest was piqued, general surgeons still considered laparoscopy a "blind" procedure, fraught with risks of intraabdominal injuries, and thus, did not incorporate the technique into the practice of general surgery. ${ }^{2}$

- In 1974, Dr Harrith M Hasson, MD, working in Chicago proposed a blunt minilaparotomy, which permitted direct visualization of the trocar entrance into the peritoneal cavity. It is popularly known today as Hasson's technique. ${ }^{15}$

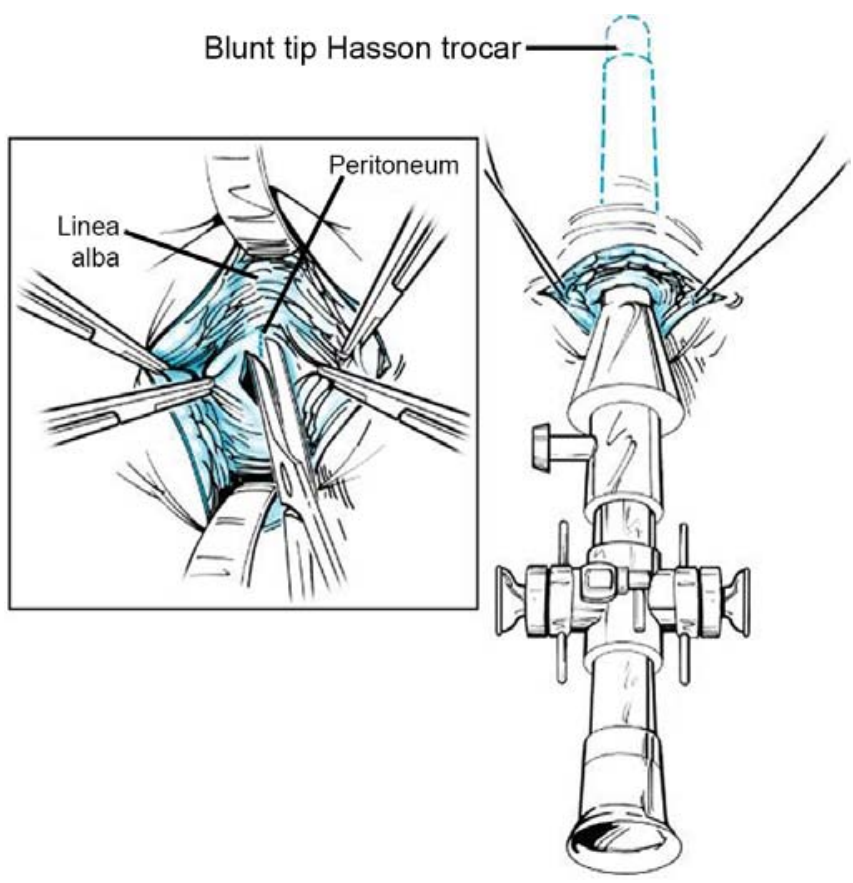

Hasson's cannula

- In the late 1970s and early 1980s, technology helped fuel the growth of minimal access surgery to what it is today.

- Surgeons had to cross a lot of hurdles due to poor light sources and camera systems.

- With the advent of charge coupled device, an excellent image of the peritoneal cavity could be viewed through a video monitor.

- The 1986 invention of computer chip television camera was a pivotal moment in progression of laparoscopy because it freed up surgeon's hands to perform procedures, which caused a paradigm shift in the major utility of laparoscopy from gynecology to general surgery in the 1990s. Introduction of automatically advancing clips made general surgeons happier to start performing procedures like removing gall bladder.

- Camran Nezhat, considered the founding "father" of operative video-laparoscopy.

- Simple operative procedures, such as aspiration of cysts, lysis of adhesions, cauterizing of neoplasms, biopsies, and tubal ligations.

First operation of laparoscopic cholecystectomy in Sept 12, 1985 by Dr Erich Mühe; 5 years later laparoscopic removal of gallbladder became gold standard. ${ }^{16}$ 


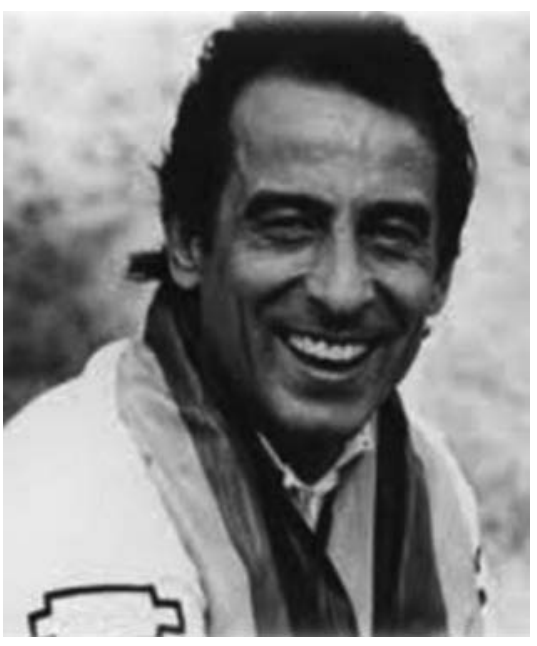

Erich Mühe

- Phillippe Mouret performed the first human laparoscopic cholecystectomy with 4 trocars in France in 1987, but did not publish feat. ${ }^{16,17}$

- McKernan and Saye performed the first laparoscopic cholecystectomy in the United States in 1988, but the technique was refined and popularized by Reddick and Olsen.

- The surgeons noticed that the patients suffer less postoperative pain, develop fewer infections, resume oral intake, and are discharged sooner than after cholecystectomy performed through a standard Kocher incision.

- Laparoscopic cholecystectomy's tremendous success, along with the flood of new technology into general surgery, stimulated surgeons to apply laparoscopic techniques to treat other gastrointestinal diseases.

\section{Gastrointestinal Procedures}

- 1988: First lap cholecystectomy in the USA, Surgiport first available

- 1989: US TV picks up on "Key Hole" surgery, EndoClip ${ }^{\mathrm{TM}}$ released

- 1990: Cuschieri (Aberdeen) warns on the explosion of endoscopy

- 1990: Bailey and Zucker in USA popularized lap anterior highly selective vagotomy with post-truncal vagotomy $^{18}$

- 1991: "Lap cholecystectomy" is accepted and becomes routine procedure

- 1991: Berci describes lap intra-op cholangiogram, while Sackier and Stroker reported laparoscopic common bile duct exploration

- 1991: First Laparoscopic fundoplication by Dallemagne ${ }^{19}$

- 1991: First laparoscopic spleenectomy by Delaitre and Maignien ${ }^{20}$

- 1991: First laparoscopic gastrectomy by Goh et al ${ }^{21}$
- 1991: First laparoscopic colectomy by Jacobs et $\mathrm{al}^{22}$ independently

- 1992: First laparoscopic placement of gastric band for morbid obesity by Bernard Cadiere ${ }^{23}$

- 1992: The National Institutes of Health Consensus Conference concludes that laparoscopic cholecystectomy is now the preferred alternative to open cholecystectomy

- 1993: First Roux-en-Y gastric bypass by Wittgrove et $\mathrm{al}^{24}$

\section{Urology Procedures}

- 1991: First nephrectomy for benign disease by Clayman et $\mathrm{al}^{25}$

- 1992: First adrenalectomy by Higashihara et $\mathrm{al}^{26}$

- 1992: First laparoscopy-assisted ileal conduit for urinary diversion by Kozminski and Partamanian ${ }^{27}$

- Zolton Szabo the pioneer laparoscopic surgeon introduced the art of endoscopic suturing technique.

- Ralph Ger, ${ }^{28}$ an enthusiastic gynecologist, described the first potential laparoscopic inguinal hernia repair in 1982.

- He described a metallic clip-applying device to close the hernia sac during laparotomy for other operations.

- His approach was applicable to hernia sacs with defects less than $1.25 \mathrm{~cm}$. He did not describe reconstructing the inguinal floor and his approach was not applicable for direct inguinal hernias.

- 1991: Intraperitoneal onlay mesh repair developed by Tay and Smoot, effective for smaller defects.

1993: Arregui et $\mathrm{al}^{29}$ and Dion and Morin ${ }^{30}$ report first transabdominal preperitoneal and McKernon and Laws report first totally extraperitoneal repair.

- Tehemton Udwadia of Hinduja Hospital, Mumbai is accepted by most as the father of laparoscopic surgery in India. Prof TE Udwadia performed the first laparoscopic cholecystectomy in India in 1990.

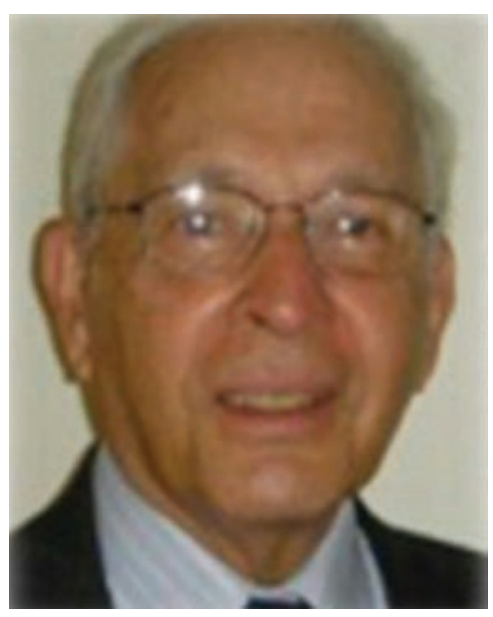

TE Udwadia 
- C Palanivelu of GEMS Hospital Coimbatore established Coimbatore institute of gastrointestinal endosurgery in 1991, developed many advances in laparoscopic surgery, and contributed significantly to the growth of minimal access surgery in Southern India around the same time. His work on the pancreas has been appreciated internationally. He was awarded the BC Roy award twice by the President of India for his contribution in minimal access surgery.

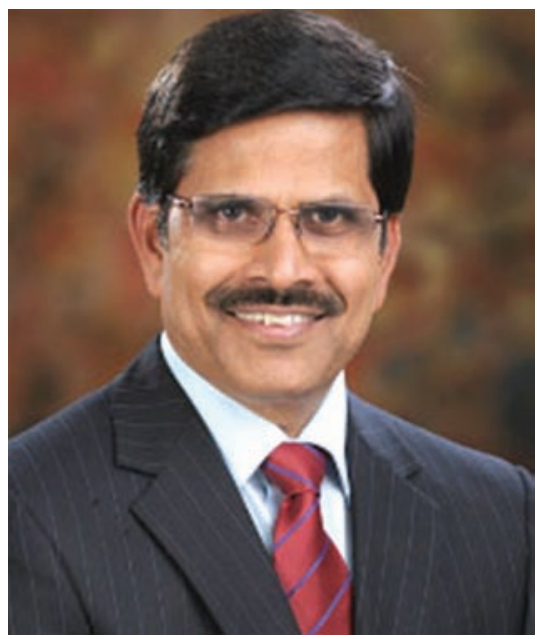

C Palanivelu

- Pradeep Chowbey of Sir Gangaram Hospital made laparoscopic cholecystectomy popular and acceptable in New Delhi and Northern India with his efforts in the early 1990s. He was awarded the Padma Shri by the President of India for his contribution.

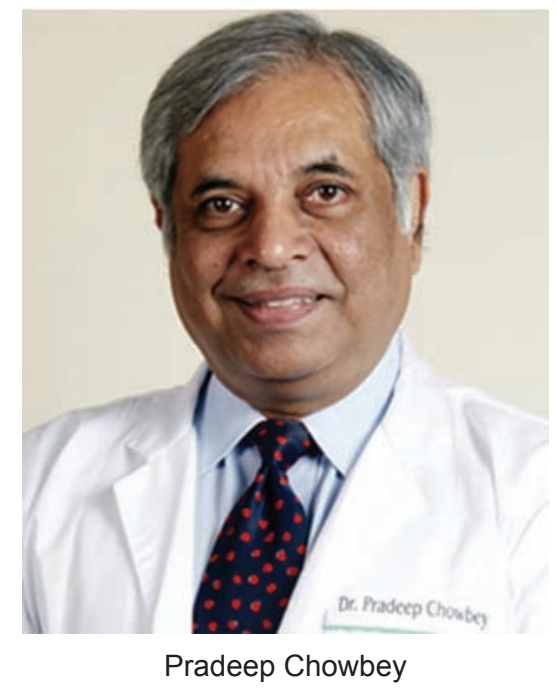

\section{Advances in Minimally Invasive Surgery}

- Single-incision laparoscopic surgery (SILS)

- Natural orifice transluminal endoscopic surgery (NOTES)

- Robot assisted

- TeleSurgery
- Advances in instruments/energy sources/light sources/optics

\section{Single-incision Laparoscopic Surgery}

- Instead of making several small incisions for the insertion of multiple trocars and instruments, make one incision and use this to deploy a multiport system.

- The first documented procedures of significance occurred in the late 1990s.

- This approach has recently seen more publicity and excitement as surgeons continue to develop techniques to evolve surgery to less invasive approaches. The first described single-port laparoscopy (SPL) procedure was a gall bladder removal in 1997.31,32

- Since that time, thousands of SPL procedures have been successfully performed in the United States, from general surgery to urologic, gynecologic, and bariatric surgery applications.

\section{Single-port Access Surgery}

\section{Benefits}

- Cosmetic (one hidden scar = no scars)

- Less pain

- Less risk of infections/hernias

\section{Disadvantages}

- Learning curve

- Takes longer

- Cost

\section{NOTES}

- Natural orifice transluminal endoscopic surgery.

- A technique that uses natural orifices (e.g., the mouth) as access points and employs both endoscopic and laparoscopic methods with the endoscope as the main platform.

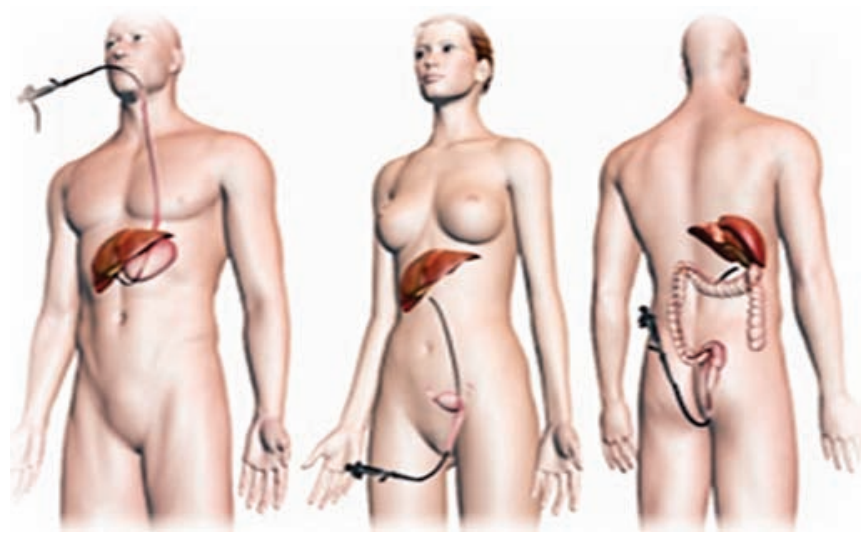

- Originally described in animals by researchers at Johns Hopkins University (Dr Anthony Kalloo et al). 
- Transgastric appendectomy in humans in India (by Dr GV Rao and Dr N Reddy).

- On June 25, 2007 Swanstrom and colleagues reported the first human transgastric cholecystectomy.

- In Johns Hopkins School of Medicine, surgeons removed a healthy kidney from a woman donor using NOTES in 2008; the surgery was called transvaginal donor kidney extraction. ${ }^{33,34}$

- Benefits:

- Cosmetic

- Less pain

- Faster recovery

- Less risk of wound infections/hernias

- Disadvantages:

- Learning curve

- Takes longer

- Problems with closing enterotomies

\section{Robotic Surgery}

- Food and Drug Administration approved in 2000

- Console located away from patient, surgeon uses play station type controls

- Master/slave concept

- Enhances safety of surgeon's movements and increases accuracy

The very first surgical robot was used in an orthopedic surgical procedure on March 12, 1984, at the UBC Hospital in Vancouver. Over 60 arthroscopic surgical procedures were performed in the first 12 months.

- In 1985, a robot, the Unimation Puma 200, was used to place a needle for a brain biopsy using computed tomography guidance.

- In 1992, the PROBOT, developed at Imperial College London, was used to perform prostatic surgery by Dr SenthilNathan at Guy's and St. Thomas' Hospital, London. This was the first pure robotic surgery in the world.

- The ROBODOC from Integrated Surgical Systems (working closely with International Business Machines Corporation) was introduced in 1992 to mill out precise fittings in the femur for hip replacement. Further development of robotic systems was carried out by SRI International and Intuitive Surgical with the introduction of the da Vinci Surgical System and Computer Motion with the AESOP and the ZEUS robotic surgical system. The first robotic surgery took place at The Ohio State University Medical Center in Columbus, Ohio under the direction of Robert E Michler.

ZEUS was used for:

- Fallopian tube reconnection in July 1998;

- A beating heart coronary artery bypass graft in October 1999;
- And the Lindbergh Operation, which was a cholecystectomy performed remotely in September $2001 .^{35-38}$

- Benefits:

- More precise/range of motion

- The three-dimensional vision/magnified

- More comfortable for surgeon

- Can be done remotely

- Disadvantages:

- Lack of haptics

- Expensive

- Long set up/procedure time

- No judgment

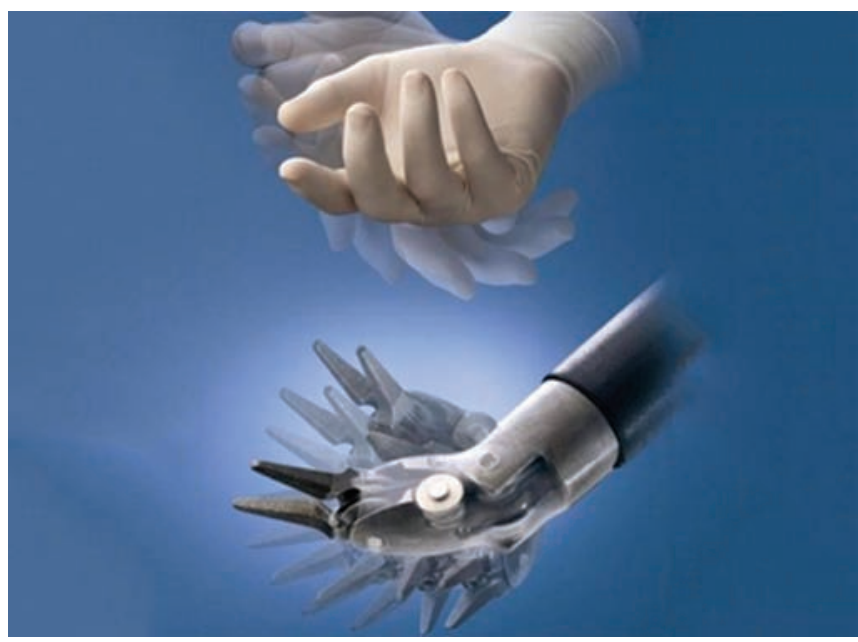

- Commonly used for:

- Urology (prostatectomy)

- Cardiac (heart surgery)

- Gynecology (hysterectomy)

- General surgery

- Thyroidectomy

\section{Telesurgery}

- Also known as remote surgery. ${ }^{39}$

- The ability for a surgeon to perform surgery on a patient that is not physically in the same location.

- It combines elements of robotics and cutting-edge communication technology.

- To perform surgery in remote locations.

- For example:

- Treating injured soldiers on or near the battlefield

- Collaborating and mentoring during surgery by surgeons around the globe

- To be utilized as a teaching tool in:

- Training new surgeons

- Assisting and training surgeons in developing countries

- Will be instrumental if astronauts are to travel to Mars or other planets-performing surgical procedures in space 


\section{Advancement in Laparoscopic Instruments}

Over the last two decades, there have been great advancements in laparoscopic instrumentation with respect to advanced cameras, newer light sources, Vicky assistant, electrocautery devices, and advanced simulators.

\section{CONCLUSION}

Technological advancements have produced progressively smaller laparoscopic instruments and higher quality imaging that allow laparoscopic surgeons to perform precise dissection with minimal bleeding through most dissection planes, and the major limitations of standard laparoscopy procedures are overcome with these advances. ${ }^{40}$

\section{CLINICAL SIGNIFICANCE}

The introduction and evolution of minimally invasive surgery has drastically changed the entire scenario of the ways in which surgeons are treating the patients. With the introduction of various innovative technologies like high-definition television, video systems, integrated digital reporting, head-mounted displays, surgical robotics, virtual reality training and integration of various modalities like ultrasound, computed tomography, and magnetic resonance imaging, the surgeon has better knowledge of the disease, thereby, treating the patient more effectively.

Ultimately, the patients are getting benefitted from this unified approach, which integrates all the innovations for the benefit of mankind.

\section{ACKNOWLEDGMENT}

We would like to acknowledge Dr C Palanivelu for his contribution to the field of minimal access surgery as well as the literature available on the subject.

\section{REFERENCES}

1. Vecchio R, MacFayden BV, Palazzo F. History of laparoscopic surgery. Panminerva Med 2000 Mar;42(1):87-90.

2. Semm K. Atlas of gynecologic laparoscopy and hysteroscopy. Philadelphia (PA): WB Saunders; 1977. p. 7-14.

3. Edmonson JM. History of the instruments for gastrointestinal endoscopy. Gastrointest Endosc 1991 Mar-Apr; 37(Suppl 2):827-856.

4. Gunning JE. The history of laparoscopy. J Reprod Med 1974 Jun;12(6):222-226.

5. Belt AE, Charnock DA. The cystoscope and its use. In: Cabot H, editor. Modern urology. Philadelphia (PA): Lea \& Febiger; 1936. p. 15-50.

6. Davis CJ, Filipi JC. A history of endoscopic surgery. In: Arregui ME, Fitzgibbons RJJ, Katkhouda N, McKernan JB, Reich H, editors. Principles of laparoscopic surgery - basic and advanced techniques. New York (NY): Springer-Verlag. p. 3-20.
7. Marlow J. History of laparoscopy, optics, fiber optics, and instrumentation. Clin Obstet Gynecol 1976 Jun;19(2):261-275.

8. Nitze M. Eine neue Beobachtungs-und Untersuchungs methode fur harnrohre, Harnblase und Rectum. Wien Med Wochcnschr 1879;24:649-652.

9. Kelling G, Ueber Oesophagoskopie, Gastroskopie and Kolioskopic. Munch Med Wochenschr 1902;1:21-24.

10. Kelling G. Ueber die Mogliehkcit die Zystoskopie bei Untersuchungen seroser Hohungen anzuwcnden. Munch Med Wochenschr 1910;45:2358.

11. Boyce HW. Laparoscopy. In Schiff L, Schiff R, editors. Diseases of the liver. Philadelphia (PA): IB Lippincott; 1982. p. 333-348.

12. Orndoff $\mathrm{BH}$. The peritoneoscope in diagnosis of diseases of the abdomen. J Radiol 1920;1:307-325.

13. Veress J. Neues Instrument zur Ausfuhrung von Brustoder Bauchpunktionen und Pheumothoraxbehandlung. Deutsche Med Wochenschr 1938;64:1480-1481.

14. Hopkins HH. The modern urological endoscope. In: Gow JG, Hopkins HH, editors. Handbook of urological endoscopy. Edinburgh: Churchill Livingstone; 1978. p. 20-33.

15. Hasson HM. Open laparoscopy vs. closed laparoscopy: a comparison of complication rates. Adv Plan Parent 1978;13(3-4):41-50.

16. Alexander G, Emma J. Laparoscopic surgery historical perspectives In: Zucker K, editor. Surgical laparoscopy. Philadelphia (PA): Lippincott Williams and Wilkins; 2001. p. 3-11.

17. Litynski Z. High lights in history of laparoscopy. Frankfurt: B Bernert Verlag; 1996.

18. Zucker KA, Bailey RW. Laparoscopic truncal and selective vagotomy for intractable ulcer disease. Semin Gastrointest Dis 1994 Jul;5(3):128-139.

19. Dallemagne B, Weerts JM, Jehaes C, Markiewicz S, Lombard R. Laparoscopic Nissen fundoplication: preliminary report. Surg Laparosc Endosc 1991 Sep;1(3):138-143.

20. Delaitre B, Maignien B. Splenectomy by the laparoscopic approach. Report of a case. Presse Med 1991 Dec 21-28; 20(44):2263.

21. Goh P, Tekant Y, Isaac J, Kum CK, Ngoi SS. The technique of Iaparoscopic Billroth II gastrostomy. Surg Laparosc Endosc 1992 Sep;2(3):258-260.

22. Jacobs M, Verdeja JC, Goldstein HS, "Minimally invasive colon resection (laparoscopic colectomy)," Surgical Laparoscopy \&amp; Endoscopy 1991;1(3):144-150.

23. Cadiere GB, Favretti F, Bruyns J, et al. Gastroplastie par celiovideoscopie:technique. J Celio Chir 1994;10:27-33.

24. Wittgrove AC, Clark CW, Tremblay LJ. Laparoscopic gastric bypass, Roux en-Y: preliminary report of five cases. Obes Surg 1994 Nov;4(4):353-357.

25. Clayman RV, Kavoussi LR, Soper NJ, Dierks SM, Meretyk S, Darcy MD, Roemer FD, Pingleton ED, Thomson PG, Long SR. Laparoscopic nephrectomy: initial case report. J Urol 1991 Aug;146(2):278-282.

26. Higashihara E, Tanaka Y, Horie S, Aruga S, Nutahara K, Homma Y, Minowada S, Aso Y. A case report of laparoscopic adrenalectomy. Nippon Hinyokika Gakkai Zasshi 1992; 83(7):1130-1133.

27 Kozminski M, Partamian KO. Case report of laparoscopic ileal loop conduit. J Endourol 1992;6:147-50.

28. Ger R. The management of certain abdominal herniae by intra-abdominal closure of the neck of the sac. Preliminary 
communication. Ann R Coll Surg Engl 1982 Sep; 64(5): 342-344.

29. Arregui ME, Davis CJ, Yucel O, Nagan RF. Laparoscopic mesh repair of inguinal hernia using a preperitoneal approach: a preliminary report. Surg Laparosc Endosc 1992 Mar;2(1):53-58.

30. Dion YM, Morin IJ. Laparoscopic inguinal herniorrhaphy. Can J Surg 1992 Apr;35(2):209-212.

31. Navarra G, Pozza E, Occhionorelli S, Carcoforo P, Donini I. One-wound laparoscopic cholecystectomy. Br J Surg 1997 May;84(5):695.

32. Piskun G, Rajpal S. Transumbilical laparoscopic cholecystectomy utilizes no incisions outside the umbilicus. J Laparoendosc Adv Surg Tech A 1999 Aug;9(4):361-364.

33. Sanchez Margallo FM, Asencio JM, Tejonero MC, Pérez FJ, Sánchez MA, Usón J, Pascual S. Technical feasibility of totally natural orifice cholecystectomy in a swine model. Minim Invasive Ther Allied Technol 2008;17(6):361-364.

34. Surgeons remove healthy kidney through Vagina. Retrieved 2009 Feb 3. Available from: InfoNIAC.com.
35. Kwoh YS, Hou J, Jonckheere EA, Hayall S. A robot with improved absolute positioning accuracy for CT guided stereotactic brain surgery. IEEE Trans Biomed Eng 1988 Feb;35(2):153-161.

36. ROBODOC: Surgical Robot Success Story [PDF]. Retrieved 2013 Jun 25.

37. Meadows M. Computer-assisted surgery: an update. FDA Consumer Magazine. Food and Drug Administration. Archived from the original 2009 Mar 1.

38. McConnell PI, Schneeberger EW, Michler RE. History and development of robotic cardiac surgery. Probl Gen Surg 2003;20(2):20-30.

39. Liverneaux P, Berner S, Bednar M, Parekattil S, Ruggiero G, Selber J et al, editors. Telemicrosurgery - Robot Assisted Microsurgery, 2013. DOI: 10.1007/978-2-8178-0391-3

40. Boppart SA, Deutsch TF, Rattner DW. Optical imaging technology in minimally invasive surgery. Current status and future directions. Surg Endosc 1999 Jul;13(7):718-722. 